\title{
Closed Extension Block Technique for Treatment of Osseous Mallet Injury
}

\section{Çekiç Parmak Kemiği Yaralanmasının Tedavisinde Ekstensiyon Blok Yöntemi}

\section{Hakan Başar', Mustafa Erkan İnanmaz', Onur Başçı², Motasım Bawaneh², Betül Başar³, Kamil Çağı Köse'}

'Department of Orthopedics Surgery, Sakarya University Training and Research Hospital

${ }^{2}$ Department of Orthopedics Surgery, Marmara University School of Medicine

${ }^{3}$ Akyazı State Hospital, Department of Physical Medicine and Rehabilitation

Yazışma Adresi / Corresponding to:

Uzm. Dr. Hakan Başar. Eski Kazımpaşa caddesi yolu Arabacıalanı mah. Akkent sitesi No: 156/25 Serdivan 54100 Sakaraya - Türkiye GSM: 05054418608 e-mail hbasar80@hotmail.com

Objectives: We analyzed the clinical and radiological outcomes of percutaneos extension block technique for treatment of osseous mallet injury.

Methods: We included 36 patients who had osseous mallet finger $\geq 20 \%$ articular surface involvement. We controlled 29 men, 7 women followed mean 18,5 ( Range 8 - 24) months.

Radiologic evaluation was made according to the Doyle classification and 25 injuries were classified type IVb, 11 injuries were classified type IVc. Final evaluation were made according to Crawford evaluation criteria and distal interphalangeal joint motion.

Results: The preoperative avarage articular surface involvement was 39,7\% (Range 20 - 60). The DIP joint subluxation was seen in 6 patients who had $\geq 50 \%$ articular surface involvement. Clinical results, according to the Crawford criteria, were excellent in 30 ( 83,3\%) patients, good in 4 patients ( $11,1 \%$ ), moderate in 2 patients $(5,5 \%)$. The average extension lag was $3,1^{\circ}\left(0^{\circ}\right.$ to $\left.17^{\circ}\right)$, and the average final active flexion of DIP joint was $75,1^{\circ}\left(50^{\circ}\right.$ to $\left.80^{\circ}\right)$. Bone union was showed in all cases radiographically at the final control.

Conclusion: The extension block technique is a minimal invasive treatment technique. This technique has decreased the complications of the open surgical treatments. This technique when properly applied has been given functionally satisfactory results. The experience of the surgeon is very effective over the result of the patients.

Keywords: Mallet Finger Surgery, Extension Block. 


\section{Introduction:}

Mallet injuries are detachment of the terminal extensor tendon, from the base of the distal phalanx either directly or in association with a fracture. ${ }^{1}$

Due to the difficulties in following up the closed reduction stably in the osseous mallet finger, surgical treatment is generally recommended for fractures with bone fragments that occupy one third or more of the joint surface and fractures associated with subluxation toward the palmar side. ${ }^{2,3}$

During open reduction and fixation with pull-out wires or Kirschner wires has disadvantages. The bone fragments are often small, they break, the maintaince of the reduction is difficult. The reduction lost may be caused the non-union or mal-union and poor range of motion. Also open surgery may be caused extension lags, permanent nail deformities, skin necrosis, pin track infection and osteomyelitis. ${ }^{4}$

Percutaneous procedures have advocated by some authors because of these complications. We evaluated long term outcomes of the extension block fixation technique which was described by Ishiguro for the first time. ${ }^{5}$

\section{Material and Method:}

36 patients diagnosed with mallet fracture between January 2006 and January 2012 were involved in the study. The patients with open fractures, comminuted fractures and less than $20 \%$ articular surface fractures were not involved in the study. The pre-operative ages, genders, Doyle classification of mallet finger injuries were evaluated. Pre-operative lateral radiographs of the finger were used to determine the presence of palmar subluxation of the distal phalanx, fragment displacement and fragment size. Anterior-posterior radiographs were used to exclude comminution. The informed consent was obtained from all patients.

\section{Surgical Technique}

After the digital block application, the DIP joint was maximally flexed. First a $\mathrm{K}$ wire was passed the extensor tendon at a 45 degree angle into the middle phalanx, just dorsal and proximal to the fracture fragment. This first wire took role as a extension block during DIP joint extension. The second wire was placed longitudinally from distal phalanx to middle phalanx across the DIP joint to maintain extension and reduction. The K-wires were cut and bent. Postoperative volar extension splint was applied for DIP joint immobilization. MP and PIP joint motion were allowed for the patients. The $\mathrm{K}$ wires were pulled at 4 week and pasive and active DIP joint motions were started .The volar extension splint' usage was continued for 2 weeks more.

All of the surgical procedures were performed by the same hand surgeon.

The physical and radiographic controls of the patients were carried out as the 1st month, 6th month annual controls. Radiographies were reviewed for displacement, fracture size, malunion and nonunion. Additionally, evaluation of the clinical results was carried out using range of motion, extensor lag, tender dorsal prominences, and complications (nail deformity and skin necrosis) and Crawford evaluation criteria. Active and passive ranges of motion were measured by using a goniometer.

\section{Results:}

Mean age of the pre-operative patients were 29,8 (range 18 to 42 ) and 29 of 36 patients (80,5\%) were male and $7(19,5$ $\%)$ were female. The 4 th and 5 th fingers were the most frequently involved finger ${ }^{12}$, followed by the 1 st fingers ${ }^{5}$, the 2 nd fingers ${ }^{4}$ and the 3 th fingers ${ }^{3} .27$ patients had mallet injury in dominant hand, 9 patients had in non-dominant hand. Based on the Doyle classification, 25 injuries were classified type IVb, 11 injuries were classified type IVc (Figure 1).

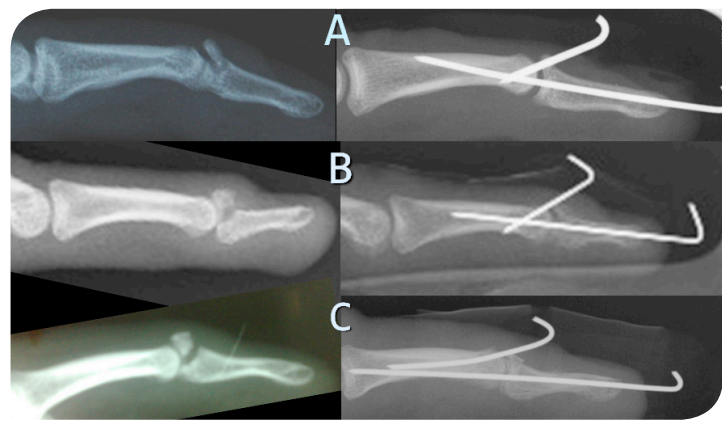

Figure 1-A: The avarage articular surface involvement was 30\%. Figure 1-B: The avarage articular surface involvement was $50 \%$ and DIP joint subluxation was seen

Figure 1-C: The avarage articular surface involvement was $60 \%$. 
The avarage articular surface involvement was 39,7\% ( Range $20-60$ ). The DIP joint subluxation was seen in 6 patients who had $\geq 50 \%$ articular surface involvement (Figure 1-B). First closed reduction was tried on all injuries than extension block treatments were applied.

At mean 18,5 ( Range 8 - 24) months controls of 36 patients involved in the study, according to the Crawford criteria, the results were excellent in 30 ( 83,3\%) patients, good in 4 patients $(11,1 \%)$, moderate in 2 patient $(5,5 \%)$. The average extension lag was $3,1^{\circ}\left(0^{\circ}\right.$ to $\left.17^{\circ}\right)$, and the average final active flexion of DIP joint was $75,1^{\circ}\left(50^{\circ}\right.$ to $\left.80^{\circ}\right)$ ( Figure 2 ).

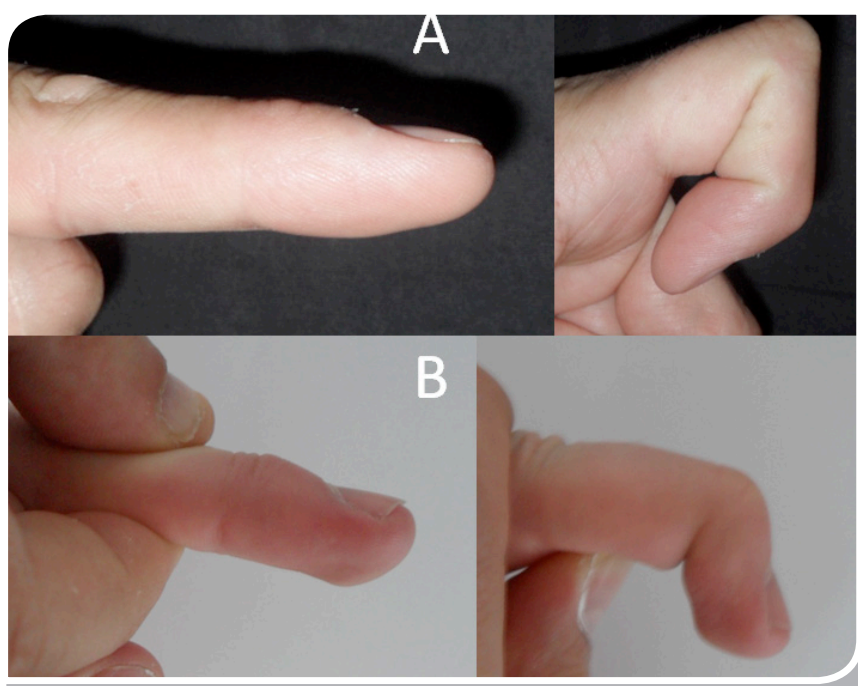

Figure 2-A: Postoperative 20 mouth clinical control picture. It is seen that range of motion of 2 nd finger was fine.

Figure 2-B: Postoperative 16 mouth clinical control picture. It is seen that there was $10^{\circ}$ extansion lag, no flexion limitation.

Bone union was showed in all cases radiographically at the final control. An intra-articular step off of less than $1 \mathrm{~mm}$ was present in 6 joints. Bone union was showed at these patients and dorsal prominance was showed at 2 of these patients. 4 of these patients had full DIP joint motion but 2 of these patients had $14,5^{\circ}$ extension lag ( Figure 3 ).

No case has wire bottom infection, skin necrosis, reflex sympathetic dystrophy, swan-neck deformity, fragmentation of the fracture, nail bed injury, pin migration. All of the patients were able to return to their previous task.

Discussion:
An untreated mallet injury is painful. The swan-neck deformity develops due to compensatory hyperextension at the PIP joint of the finger $(6,7)$. The oseous mallet finger constitutes about 5 - $10 \%$ of mallet finger injuries (8).
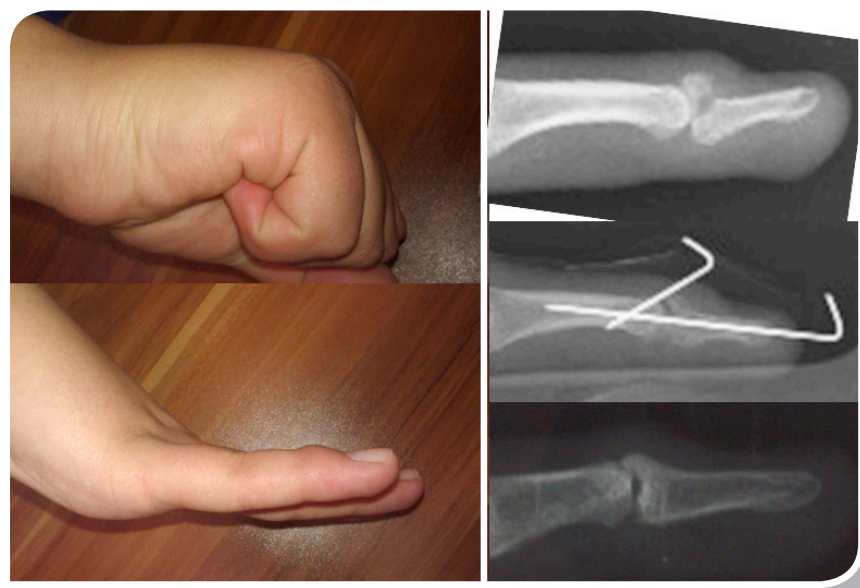

Figure 3: Postoperative 24 mouth clinical control picture, preoperative, early postoperative and postoperative 24 mounth radiographies. The avarage articular surface involvement was $60 \%$. There was no limitation of DIP joint motion.

The management of acute mallet fingers with a small fracture fragment involving less than one-third of the articular surface of the distal phalanx is usually done by continuous distal interphalangeal joint volar splinting in extension for 6 to 8 weeks. Frequent follow-up evaluations are essential for conservative treatment ${ }^{1}$. The complications ( skin maceration, tender dorsal prominance, joint stiffness, swan neck deformity, extansion deficience ) have been reported for conservative treatment ${ }^{9}, 10$. Approximately $10^{\circ}$ extansion deficience has been reported after conservative treatment in $40 \%$ to $70 \%$ of patients ${ }^{11,12}$.

The treatment of mallet fractures involving more than onethird of the articular surface is controversial. The incidance of complication ( permanent nail deformity, marginal skin necrosis, avscular necrosis of fragment, osteomyelitis ) was 33\% to $53 \%$ for open surgical treatment ${ }^{1,13}$.

The extension block technique is a minimal invasive treatment technique. This technique has decreased the complications of the open surgical treatments. Pin-tract infection is most potential complication of this technique. Regular follow-up 
is important to prevent this complication. In our study, we didn't see pin-tract infection. $78 \%$ to $92 \%$ excellent and good functional results have been reported 9,14 . We obtained $34 / 36 \%$ excellent and good results in our study. A perceived disadvantage of extension block technique might be the need for fluoroscopy as the other closed surgical procedures. The other disadvantage is articular cartilage damage as a result of $\mathrm{K}$ wire insertion which might lead to osteoarthritis. Repe- tative attempt at pin insertion is increased articular cartilage damage. The experience of the hand surgery is very important for this reason. In our study we didn't see osteoarthritis at the patients.

This technique when properly applied has been given functionally satisfactory results. The experience of the surgeon is very effective over the result of the patients.

\section{References}

1. Wehbé MA, Schneider $\mathrm{LH}$. Mallet fractures. J Bone Joint Surg 1984;66(A):658-69.

2. Lubahn JD. Mallet finger fractures: a comparison of open and closed technique. J Hand Surg 1989:14(A):394-6.

3. Stark HH. Gainor BJ. Ashworth CR. et al. Operative treatment of intraarticular fractures of the dorsal aspect of the distal phalanx of digits. J Bone Joint Surg 1987:69(A):892-6.

4. Kang HJ, Shin SJ, Kang ES. Complications of operative treatment for mallet fractures of the distal phalanx. J Hand Surg 2001, 26(B): 28-31.

5. Ishiguro T, Inoue K, Matsubayashi T, Ito T, Hashizume N. A new method of closed reduction for mallet fractures. J Jap Soc Surg Hand 1988;5:444-7.

6. Grundberg $A B$, Reagan DS. Central slip tenotomy for chronic mallet finger deformity. J Hand Surg 1987;12(A):545-7.

7. Evans D, Weightman B. The Pipflex splint for treatment of malletfinger. Hand Surg 1988;13(B):156-8.

8. Darder-Prats A, Fernandez-Garcia E, Fernandez-Gabarda R: Treatment of mallet finger fractures by the extension-block K-wire technique. J Hand

Surg 1998; 23(B): 802-5

9. Hofmeister EP, Mazurek MT, Shin AY, Bishop AT. Extension block Pinning for Large Mallet Fractures. J Hand Surg 2003,28(A):453-9

10. Rayan GM, Mullins PT. Skin necrosis complicating mallet finger splinting and vascularity of the distal interphalangeal joint overlying skin. J Hand Surg 1987,12(A): 548-52

11. Abouna JM, Brown $\mathrm{H}$. The treatment of mallet finger: the results in a series of 148 consecutive cases and a review of the literature. $\mathrm{Br} J$ Surg 1968; 55:653-67

12. Mikic Z, Helal B. The treatment of the Mallet finger by the Oakley splint The Hand 1974;6:76-81.

13. Stern PJ, Kastrup JJ. Complications and prognosis of treatment of mallet finger. J Hand Surg 1988;13(A):329-34

14. Pegoli L, Toh S, Arai K, Fukuda A, Nishikawa S, Vallejo G. The Ishiguro extension block technique for the treatment of mallet finger fracture: indications and clinical results. J Hand Surg 2003,28(B):1:15-7 